\title{
Multiple distal coronary artery thrombosis in acute myocardial infarction: a rare presentation
}

\author{
Kunal Mahajan, Aditya Batra, Abhishek Gupta, Vinod Singla
}

Department of Cardiology, Holy Heart Advanced Cardiac Care and Research Centre, Rohtak, Haryana, India

\section{Correspondence to}

Dr Kunal Mahajan,

kunalmahajan442@gmail.com

Accepted 9 July 2018

\section{DESCRIPTION}

A 47-year-old man was referred to us with severe retrosternal chest pain and diaphoresis 6 hours back. Except for smoking, he had no other risk factors for coronary artery disease. The patient was haemodynamically stable and physical examination was unremarkable. The ECG done at the referral hospital revealed changes suggestive of inferolateral wall ST elevation myocardial infarction (STEMI) (figure 1), and left circumflex coronary artery was the most

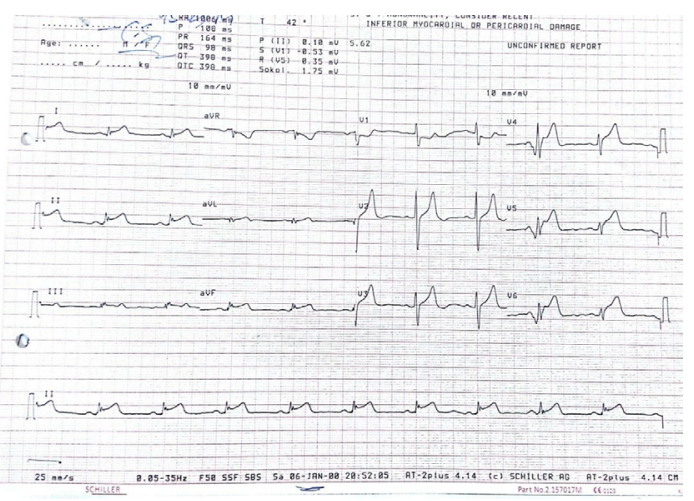

Figure 1 ECG showing ST elevation in leads I, II, III, aVF and $\mathrm{V} 4-\mathrm{V} 6$ suggestive of inferolateral wall myocardial infarction. ST elevation in lead II>III is suggestive of left circumflex coronary artery as the culprit vessel.

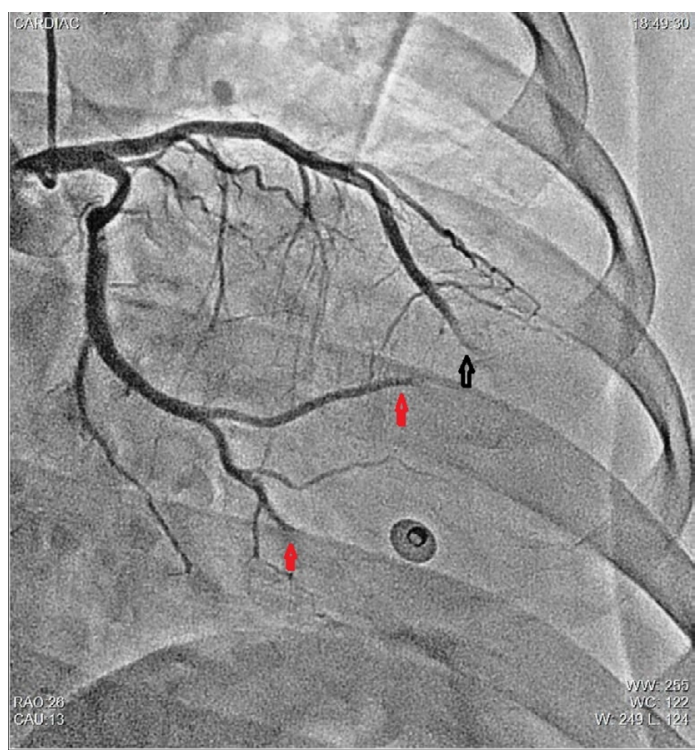

Figure 2 Coronary angiogram showing thrombotic occlusion of the distal left anterior descending coronary artery (black arrow) and the terminal branches of the major obtuse marginal artery (red arrows).

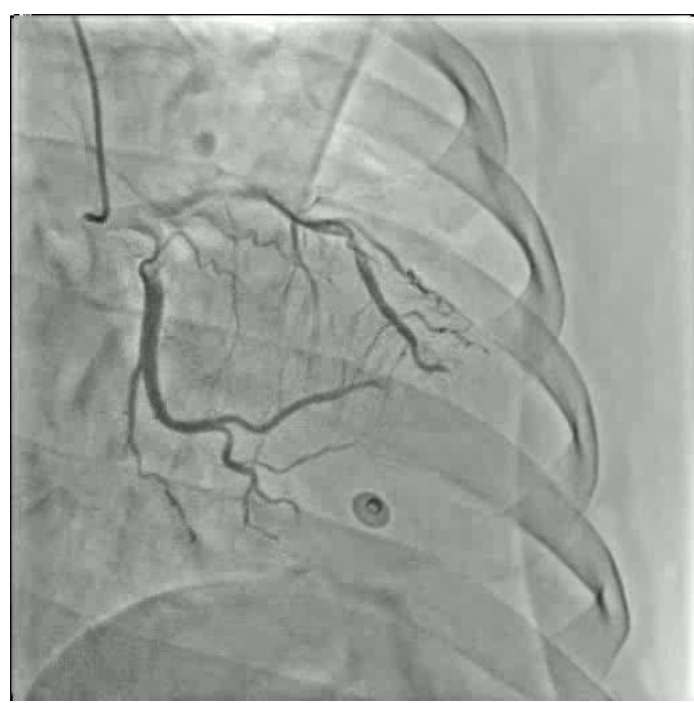

Video 1 Coronary angiogram showing distal thrombotic occlusion of multiple coronary arteries.

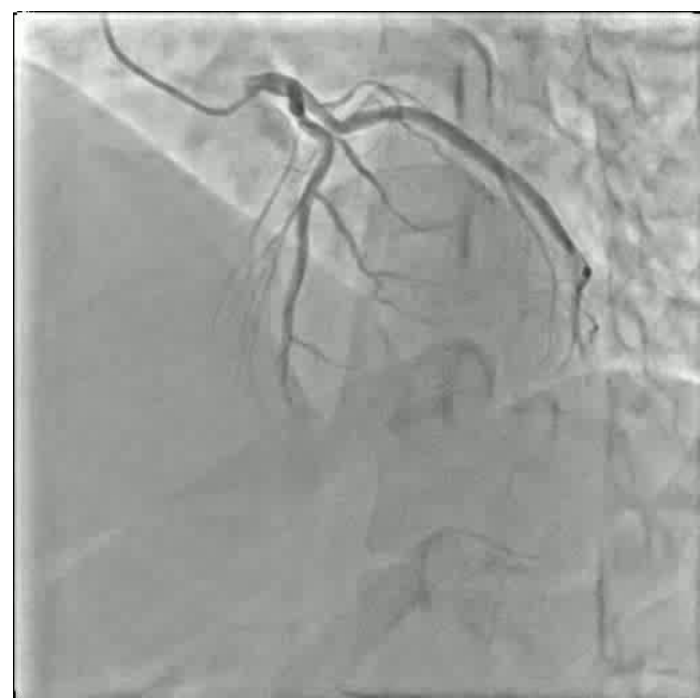

Video 2 Coronary angiogram, left anterior oblique view, showing distally occluded left anterior descending and terminal obtuse marginal branches.

likely culprit vessel. Echocardiogram revealed hypokinesia of the inferolateral wall with mild mitral regurgitation. The patient was immediately shifted to the catheterisation lab and coronary angiogram was done. However, to our surprise, both the terminal branches of the major obtuse marginal artery and the distal segment of the left anterior descending coronary artery were occluded by thrombi in their distal segments (figure 2, videos 1 and 2). Because of the distal location of the thrombi, we decided against 


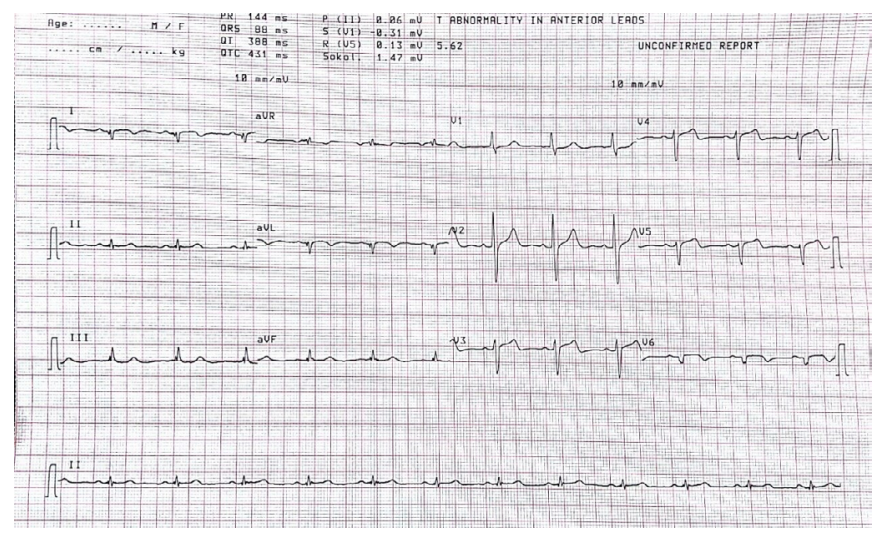

Figure 3 ECG on admission at our hospital.

percutaneous coronary intervention and thrombus aspiration. Moreover, the patient had become chest pain-free by that time. On repeat ECG, ST elevation had settled and Q waves were seen in leads 1, aVL and V6 (figure 3). Therefore we decided against thrombolysis also and kept the patient on unfractionated heparin infusion for 24 hours along with routine STEMI care. The check angiogram done 24 hours later revealed complete recanalisation of the occluded vessels with no evidence of residual thrombus (figure 4 and video 3 ).

Simultaneous thrombosis of multiple coronary arteries in STEMI is an uncommon angiographic finding and has generally been associated with a poor prognosis. ${ }^{1}$ A possible pathogenic mechanism is multiple plaque ruptures as a result of diffuse inflammatory process 'pan-arteritis' involving multiple coronary arteries. ${ }^{2}$ Another hypothesis states that ischaemic event in one coronary artery might lead to impairment of blood flow in the other vessels (secondary to transient ventricular dysfunction or

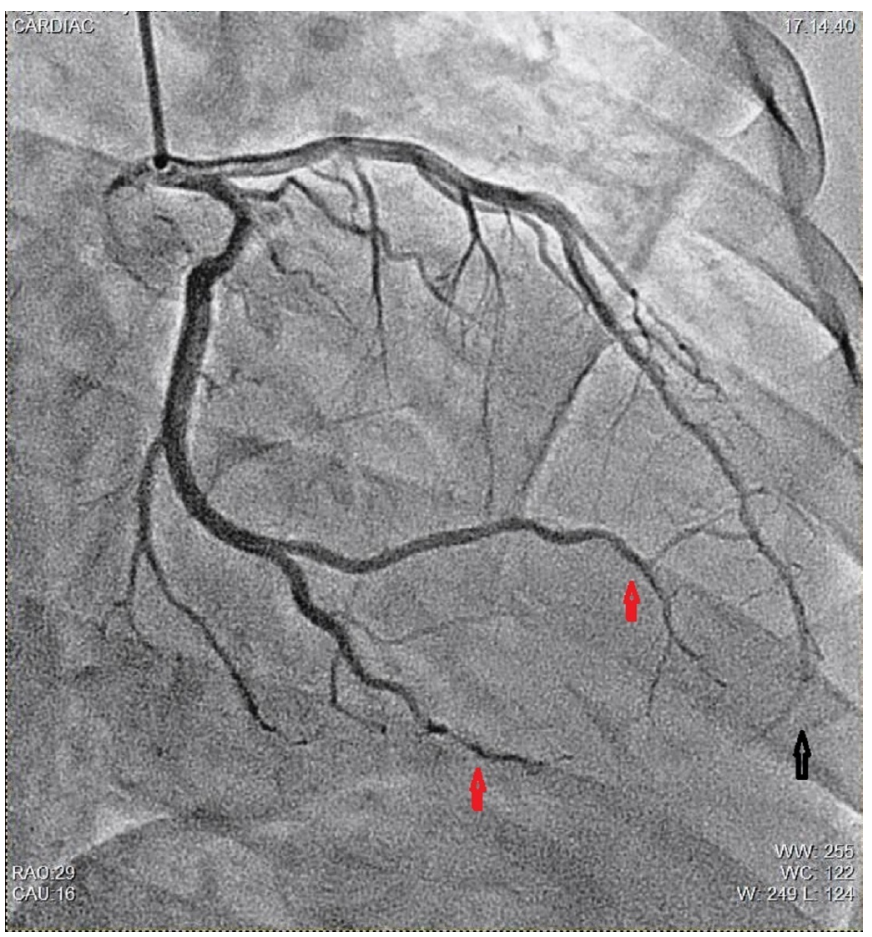

Figure 4 Repeat coronary angiogram after 24hours showing completely recanalised arteries (Black arrow points towards recanalized distal left anterior descending coronary artery, while red arrows denote recanalized terminal branches of the major obtuse marginal artery.)

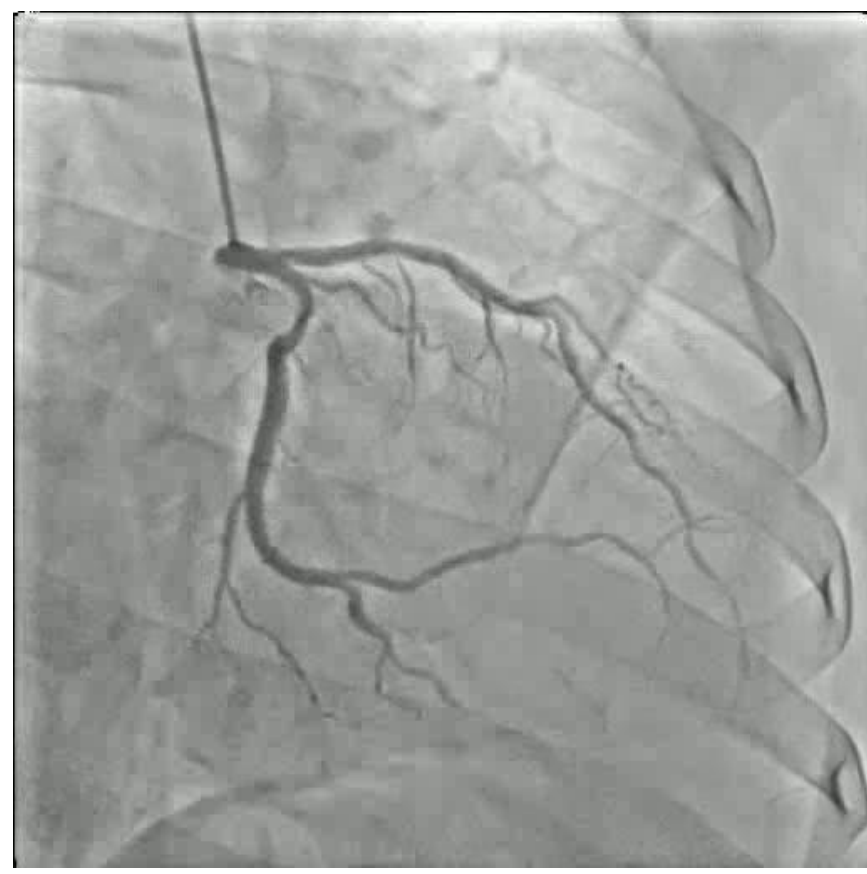

Video 3 Repeat coronary angiogram after 24 hours.

\section{Learning points}

- Thrombosis of multiple coronary arteries at the same time is an uncommon angiographic finding in ST elevation myocardial infarction (STEMI).

- The exact mechanism is still unclear; however, the role of multiple plaque ruptures as a result of diffuse inflammation of multiple coronary arteries has been suggested.

- Hereditary or acquired causes of hypercoagulability, cocaine abuse, diffuse coronary vasospasm, and aortic or mitral valve endocarditis should always be ruled out.

- Because of the scarcity of cases, ideal management strategy is still not clearly defined.

- Complete revascularisation, either by thrombolysis or percutaneous coronary intervention, should always be the aim if done timely.

arrhythmias), resulting in thrombus formation. Lastly, one must always look for identifiable causes like coronary vasospasm, cocaine abuse, aortic or mitral valve endocarditis, and acquired and hereditary causes of hypercoagulability.

Acknowledgements We acknowledge the contribution of our chief laboratory technician Mr Manish Chowdhary for providing the angiography images and videos.

Contributors $\mathrm{KM}$ and $\mathrm{AB}$ performed the coronary angiography and made the diagnosis. VS and AG were involved in the management of the patient. KM wrote the manuscript. All authors read and approved the final version of the manuscript.

Funding The authors have not declared a specific grant for this research from any funding agency in the public, commercial or not-for-profit sectors.

Competing interests None declared.

Patient consent Obtained.

Provenance and peer review Not commissioned; externally peer reviewed.

\section{REFERENCES}

1 Mahmoud A, Saad M, Elgendy IY. Simultaneous multi-vessel coronary thrombosis in patients with ST-elevation myocardial infarction: a systematic review. Cardiovasc Revasc Med 2015;16:163-6.

2 Song WJ, Koo JK, Park KH, et al. Simultaneous total occlusion of multiple distal coronary arteries in acute myocardial infarction. Korean Circ J 2011;41:622-4. 
Copyright 2018 BMJ Publishing Group. All rights reserved. For permission to reuse any of this content visit http://group.bmj.com/group/rights-licensing/permissions.

BMJ Case Report Fellows may re-use this article for personal use and teaching without any further permission.

Become a Fellow of BMJ Case Reports today and you can:

- Submit as many cases as you like

- Enjoy fast sympathetic peer review and rapid publication of accepted articles

Access all the published articles

Re-use any of the published material for personal use and teaching without further permission

For information on Institutional Fellowships contact consortiasales@bmjgroup.com

Visit casereports.bmj.com for more articles like this and to become a Fellow 